\title{
STIGMA OF MENTAL ILLNESS AMONG AMERICAN INDIAN AND ALASKA NATIVE NATIONS: HISTORICAL AND CONTEMPORARY PERSPECTIVES
}

\author{
Donna Grandbois, MS, RN \\ North Dakota State University, \\ Fargo, North Dakota, USA
}

\begin{abstract}
Among American Indian and Alaska Native (AIAN) people, the concept of mental illness has different meanings and is interpreted in various ways. This paper describes the realities of mental health care that confront AIAN people. Stigma is associated with mental illness, which can be a barrier for those individuals who are in need of mental health services. Within the context of the AIAN historical and contemporary experiences, the paper details domains that negatively influence the lives of AIAN people. Included are the failure of the U.S. government to fulfill its treaty agreements with AIAN people; the disparities in income and education, and the pervasiveness of poverty; and access to care issues. These domains help to set the stage for health disparities that frequently catapult AIAN people to early morbidity and mortality. Importantly, many of these conditions are preventable. The paper concludes with recommendations for a more diverse workforce that will include AIAN mental health professionals who are available to provide culturally competent care to AIAN people in a variety of settings.
\end{abstract}

The purpose of this paper is to describe several realities that confront American Indian and Alaska Native (AIAN) people who do not have adequate access to mental health care. Included in this paper are discussions about the concept of mental illness, the stigma associated

Address correspondence to Donna Grandbois, North Dakota State University, 130 Evergreen Circle NE, West Fargo, ND 58078. E-mail: dmgrandbois@gmail.com 
with mental illness, and the differences in treatment approaches between AIAN and Western medicine. Four domains that negatively impact the well-being of AIAN people also are explored: (1) the U.S. trust responsibility; (2) income, education, and poverty; (3) access to health care; and (4) health disparities among AIAN people. Throughout this paper, "AIAN" will be used when referring to both American Indian and Alaska Native populations: they have the same government-to-government relationship, and are eligible for similar federal programs under treaties and legal outcomes.

AIANs are the indigenous people of the land now occupied by the United States. Evidence indicates that indigenous people have inhabited North America for more than 75,000 years (Josephy, 1991). Prior to Columbus's landing in 1492, it is estimated that there were 8 to 12 million native people inhabiting the North American continent. They experienced few serious diseases compared with people of the Old World, the Europeans (Smedley, Stith, \& Nelson, 2003). However, after contact, AIAN people were exposed to the Old World's diseases, including smallpox, influenza, measles, typhus, malaria, leprosy, cholera, bubonic plague, gonorrhea, and chancroid. As a result, about $95 \%$ of these North American inhabitants succumbed to European conquests, politics, and diseases (Smedley et al., 2003). By 1900, only about 250,000 American Indians remained in the United States (Pedraza \& Rumbaut, 1996).

In 1955, the Indian Health Service was established. It is the designated Federal agency charged with the primary responsibility of providing health and mental health care to AIANs. Traditional medicinal practices, spirituality, and cultural ceremonies are proudly expressed in the lives of many AIANs, and could complement Western medicine beliefs and practices (Brave Heart \& DeBruyn, 1998; U.S. Department of Health and Human Services, 2001). AIAN people frequently use biomedical interventions to get relief of acute symptoms, but they use traditional health practices to address the fundamental cause of their health problems. That is, AIAN people often seek traditional practitioners to restore the sense of balance, harmony, and unity that the acute or traumatic event has caused (Buchwald, Beals, \& Manson, 2000).

Currently, the U.S. Census reports 4.1 million individuals who identify themselves as being AIAN, either alone or in combination with other ethnic groups (U.S. Census Bureau, 2002). There are over 560 federally recognized tribes and over 100 state recognized tribes, each of which has its own unique culture. Thus, there is great diversity within the AIAN people's political, social, cultural, and spiritual communities (U.S. Census Bureau, 2002). According to the U.S. Census Bureau Population Estimates, AIAN populations currently reside in numerous 
TABLE 1. American Indian and Alaska Native Population for the United States: 2000

\begin{tabular}{lc}
\hline States & Numbers of American Indians \\
\hline California & 333,346 \\
Oklahoma & 273,230 \\
Arizona & 255,879 \\
New Mexico & 173,483 \\
Texas & 118,362 \\
North Carolina & 99,551 \\
Alaska & 98,043 \\
Washington & 93,301 \\
New York & 82,461 \\
Michigan & 58,479 \\
\hline
\end{tabular}

Source: U.S. Census Bureau (February, 2002) Census 2000 summary file 1; 1990 census of population, General population characteristics (as cited in U.S. Census Bureau, February, 2002). The American Indians and Alaska Native Population: 2000. Retrieved June 1, 2005, from http://www.census.gov/prod/2002pubs/c2kbr01-15.pdf

states. See Table 1 for a delineation of the states with the highest AIAN populations. Approximately $60 \%$ of the AIAN people reside in urban areas, with the highest number of AIANs living in Los Angeles, California (U.S. Department of Health and Human Services, 2004). The urban area with the highest number of Alaska Natives is Anchorage, Alaska (Dixon \& Roubideaux, 2001).

When discussing these populations, however, caution is in order: According to the Centers for Disease Control and Prevention (2003b), there is a $40-50 \%$ misclassification of American Indians as either White or Hispanic. Misclassification arises from several causes: (a) the use of Spanish surnames to determine race; (b) personal observation by data collectors to determine race; (c) the lack of an "American Indian/Alaska Native" response category on forms; (d) inconsistent definitions of who is considered to be AIAN; and (e) federal and state recognition of tribal Nations (i.e., non-federally recognized tribal members may not identify themselves as American Indians/Alaska Natives (Burhansstipanov \& Satter, 2000). Additionally, the common practice of collapsing existing racial categories, such as Asians, Native Hawaiians and Pacific Islanders, and AIANs, into a single group of "Other" hinders the work of public policymakers, researchers, and tribal planners (Norton \& Manson, 1996; Yates, 1987). For AIAN people, the "Other" data category has the same limitations as having no information or being excluded from a study (Burhansstipanov \& Satter, 2000). This practice also is common in 
national multisite clinical trials that are funded by the National Institutes of Health (U.S. Department of Health and Human Services, 2001).

\section{STIGMA IN MENTAL HEALTH}

The burden of mental illness looms over the AIAN nations, extracting vitality and interrupting their futures. Worse, the stigma attached to mental illness often deters people from seeking help, thus prolonging illnesses that could be treated or even prevented. Before we can address this problem, however, it is of critical importance that the worldview of mental illness and stigma be understood from an AIAN perspective. Table 2 delineates some of the differences in AIAN and Western worldviews that impact the provision of culturally competent mental health care.

The origins and concept of mental illness and stigma among AIAN people remain elusive. Existing literature suggests that this construct was imposed upon AIAN people much like the tenets of Christianity were (Walker \& Ladue, 1986). However, Thompson, Walker, and Silk-Walker (1993) and Levine and Lurie (1970) stress the importance of understanding the diversity that exists among AIAN nations and ethnic groups, and caution against making "one shoe fits all" generalities. The differences in the backgrounds of two AIAN individuals might be greater than the differences between two Europeans from dissimilar countries. Deculturation (the loss of traditional ways) and reculturation (incorporating the ways of the majority), as well as intermingling among tribal groups, have over time blurred some of the tribal differences, but it would still be erroneous to assume that either the cultures or the mental health problems

TABLE 2. Worldview Differences that Impact Mental Health Care

\begin{tabular}{ll}
\hline American Indian/Alaska Native & \multicolumn{1}{c}{ Majority culture } \\
\hline - Relational, circular & - Linear, point A to B \\
- Mind, body, spirit/One & - Psyche is the focus \\
- Mystical/acceptance & - Scientific/verification \\
- Ceremonials/rituals & - Psychotherapy \\
- Tribal connectedness & - Individualism \\
- Spirituality \& balance & - Organized religions \\
- Cooperation/sharing & - Competition/winning \\
- Patience/respectful & - Assertive/forceful \\
- Present oriented & - Future oriented \\
- Herbs, plants, nature & - Psychopharmacology \\
\hline
\end{tabular}

Source: Grandbois, 2005. 
of AIAN people are all the same (Levine \& Lurie, 1970). It also would be a mistake and a disservice to assume that their expressions of mental illness or their preferred treatment modalities are or should be the same (Kleinman, 1996; Thompson, 1996; Thompson, Walker, \& Silk-Walker, 1993).

Thompson et al. (1993) found that the degree of stigma attached to a mental disorder is correlated with the level of deculturation from traditional belief systems that remains with the individual and family members. Conversely, stigma of mental illness is also related to the reculturation process that places AIAN people into the Western health belief system. The greater the deculturation and reculturation process, the more amenable the person will be to accepting the diagnostic and treatment process of the dominant culture (Hooper, 1991; Kleinman, 1996). Recognizing diversity among AIAN people makes it difficult to generalize about stigma. Thompson et al. (1993) found that some tribal groups attach very little stigma to any mental disorder, because they make limited or no distinctions between mental and physical symptoms. On the other hand, other tribal groups attach high levels of stigma to psychiatric disorders, but accept the Western method of diagnosing and treating certain other conditions. Additionally, stigma might be attached to particular events such as suicide, in part because of the recent amount of media attention that has been directed toward suicide among AIAN youth. Still, some tribal groups attach stigma to most mental disorders, including alcohol and substance abuse (Kleinman, 1996; Thompson et al., 1993).

\section{CONCEPT OF MENTAL ILLNESS AMONG AIAN GROUPS}

When considering the origins of the concept of mental illness (and stigma) it is vital that psychiatric nurses and other health care professionals become culturally competent about the traditional belief systems that are embraced by the particular AIAN groups, and the principles that they embrace in general (Thompson, 1996). For example, among various AIAN people, mental illness is viewed as: (a) a form of supernatural possession; (b) an imbalance and disharmony with the inner and outer natural forces in the world; and (c) the expression of a special gift (Thompson et al., 1993). Still other groups conceptualize mental disorders as a hopeless state, the terminal phase of an illness (Kunitz, 1983; Thompson et al., 1993). Walker and Ladue (1986) noted that, prior to European contact, there was no concept of mental illness per se. Physical illness (e.g., object intrusion or soul loss) was seen as the cause of what would be considered in Western terminology as mental illness. Among 
some AIAN groups, deviant behavior was perceived as misbehavior and was treated as such. For example, the individual might be reprimanded by his or her tribal group, or be censored from certain community and ceremonial activities. Such behaviors were not conceptualized as a mental illness (Thompson, 1996; Thompson et al., 1993). Psychotic states (e.g., hallucinations) in AIAN people were rare, and those who manifested such signs and symptoms might be thought of as having selective attributes that were not typically found among other people (Thompson et al., 1993). In current clinical practice, Thompson et al. (1993) caution that when psychotic symptoms are evaluated in an AIAN person, it is important not to exclusively apply Western criteria for determining the diagnoses and severity levels of the illnesses. The paucity of scientific literature that could help to explicate appropriate disease prevention and treatment modalities among AIAN people makes comprehensive mental health program planning difficult and, at times, ineffective (Andrew \& Krouse, 1995; Centers for Disease Control and Prevention [CDC], 2003a; Joe, 2001; Whitbeck, McMorris, Hoyt, Stubben, \& LaFromboise, 2002). Much of the available scientific literature has focused on the sociocultural aspects of internalizing and externalizing behaviors among AIAN people (Thompson, 1996). Inadequate attention has been given to exploring the meanings of mental illness and the various forms of expression that specific illness conditions manifest across the life span (Kleinman, 1996; Thompson, 1996; Thompson et al., 1993).

Among one AIAN group, the Northern Plains people, the concept of mental illness was imposed in 1889 when the first federal mental hospital for an ethnic group, "The Hiawatha Asylum for Insane Indians," was established (Yellow Bird, 2001). It was believed that a "separate institution for Native Americans was needed because they had unique mental health afflictions" (Bhatara, Gupta, \& Brokenleg, 1999, p. 767). The asylum was developed during a time when the U.S. Congress had passed a federal law that prohibited AIAN people from practicing their own customs and the spiritual rituals indigenous to their culture and ways of life (Yellow Bird, 2001). Indeed, AIAN ceremonies and spiritual rituals were considered criminal activities and were punishable by federal law.

At the same time, other deleterious actions were perpetuated against AIAN children, which, by any standard, could help to create mental and emotional states that might lead to psychiatric disorders (Garcia Coll \& Garrido, 2000). For example, Yellow Bird (2001) discussed other federal laws that supported the kidnapping of AIAN children, who were shipped hundreds and thousands of miles away from their homes to U. S. military installations and Christian boarding schools. In these environments, they 
were frequently spiritually, physically, sexually, and emotionally abused in an effort to "beat the Indian" (p. 4) out of them. Yellow Bird further states,

Nobody went to Canton to get well. Incarceration at Canton meant no medical care of any kind and what's more, incarceration there was terminal: institutional policy declared these Native people to be "defectives" and as such, procreation must be prohibited and they must be sterilized before they could be discharged. Since the superintendent did not know how to conduct sexual sterilization procedures, inmates simply remained until they died. Of the average of ten discharges per year at Canton, nine were due to death (p. 9).

The legacy of this historical mistreatment remains alive today. Most AIAN people have learned to be quite suspicious of "White people" and "White man's medicine." Among some Western-trained clinicians and researchers, this protective stance could be used as clinical evidence for a diagnosis of paranoid psychosis or paranoid personality disorder (Thompson et al., 1993). (See American Psychiatric Association Diagnosis and Statistical Manual of Mental Disorders, 2000, for a detailed discussion about the criteria for diagnoses of psychiatric disorders).

\section{Diagnostic Issues}

Questions abound about the authenticity of the Diagnostic and Statistical Manual of Mental Disorders (DSM-IV-TR.TM APA, 2000) as the gold standard for the diagnostic process for AIAN children and adults (Novins, Bechtold, Sack, Thompson, Carter, \& Manson, 1997; O’Nell, 1989). Warren (1996) posits that for AIAN people, "the word crazy doesn't mean mentally ill, it implies something like contrary, or contradictory, or going against the grain" (p. 26). In addition, O'Nell (1989) has identified and described several other additional culture-specific disorders that are manifest among some AIANs. These conditions are added in addition to the 25 syndromes listed in the DSM-IV-TR ${ }^{\mathrm{TM}}$ (APA, 2000, Appendix I) that are universally applied to all people in this society.

Pibloktoq (arctic hysteria), chidnoh (a form of ghost sickness), windigo (melancholia and delusions), schwas (spirit intrusion), and iich'aa (taboo breaking) are a few of the conditions that are of concern to AIAN individuals and family members (Trimble, Manson, Dinges, \& Medicine, 1984). Tawatl ye sni (totally discouraged) (Johnson \& Johnson, 1965) and wacinko (to pout) also are reported as important conditions among the various AIAN groups (Lewis, 1975). Furthermore, Manson, Shore, and Bloom (1985) have written about "ghost sickness" and 
"heartbreak syndrome" as examples of unique expressions of distress exhibited by AIANs. Translations of the terms cited varied from group to group but were manifested and acknowledged in some manner among many of the ethnic groups (Clifford-Stoltenberg \& Earle, 2002). Wallace (1959) described mental/physical symptoms among the Iroquois Nation that were believed to have been caused by influences outside the individual; various rituals performed by secret Iroquois societies treated them. When Lewis (1975) described the condition of "wacinko" in the American Journal of Psychiatry, he stated that the syndrome, also well known among the Oglala Sioux, had not been identified by non-indigenous physicians who had been working on or near the reservation for over 100 years (Clifford-Stoltenberg \& Earle, 2002). Lewis (1975) suggests that "mainstream clinicians" ought to consult with indigenous practitioners about the expressions of mental disorders among indigenous people. Such recommendations should become a required action and a practice guideline for all practitioners who are not culturally competent to provide quality care to AIAN people (National Institute of Mental Health [NIMH], 2001; U.S. Department of Health and Human Services, 2001).

Researchers and clinicians should know that many AIAN people traditionally embrace a relational worldview, in which wellness in all areas (i.e., social, mental, physical, and spiritual) is dependent on the proper balance and harmony in inner and outer environments (Cross, 1997). AIAN groups stress the development of the inner life, which is reflected in the outer world through respect for all things. Likewise, the events of the outer world speak to inner processes for the person. Cross (1997) emphasizes balance and harmony in relationships across multiple variables, including spiritual forces, which comprise the core of the thought processes among native people. That is to say, every event is in relation to all other events, regardless of time, space, or physical existence. Health exists only when there are balance and harmony in the inner and outer domains of life. In the relational worldview, helpers and healers are taught to understand problems through the balances and imbalances in the person's relational world. Furthermore, they are taught to see and accept complex inter-relationships that can be influenced by entering the world of the client and manipulating the balance-imbalance phenomena. These interventions are implemented within unique and multifarious contexts, cognitive sets, emotional states, and physical conditions (Kleinman, 1996; Young, 1995). Significantly, spiritual principles undergird all interventions. From this frame of reference, interventions need not be targeted to a particular symptom or cause, but are focused on improving the individual's balance and harmony circumstances. Thus, a culturally competent clinician would be one who gains an understanding of the 
complex interdependent nature of AIAN life experiences, and learns how to use physical, psychological, contextual, and spiritual forces to promote balance and harmony. From either historical or current perspectives, AIAN people do not typically perceive mental illness as separate from physical or spiritual illness. Instead, all three factors are critical in influencing and maintaining the health and well-being of individuals (Mehl-Madrona, 1997; Thompson et al., 1993). Culturally competent mental health research, policy promulgation, and clinical care for AIAN individuals and communities must embrace this worldview (Brave Heart \& DeBruyn, 1998; Edmonson, 2000; Thompson et al., 1993).

Mehl-Madrona (1997), an American Indian physician and clinical psychologist, has written, "All illness is an illness of the spirit that manifests itself in the body, mind, and emotions, and we all carry within our souls the capacity to heal ourselves" (p. 17). From a prevention and treatment perspective, the body, mind, and spirit are inexorably connected. Mehl-Madrona further suggests that an ancestral model of healing be employed that would allow clinicians to move beyond the practice of objectifying the body's parts. Furthermore, psychiatric diagnoses are inseparable from social events and coping strategies, which are essential for survival (Kleinman, 1996; Moos, 1991).

Therefore, culturally respectful, comprehensive care would require that for AIAN healers, the first step in treating a person is to listen to his or her story. The healer enters the world of the patient and works to see things through his or her eyes and thought processes. There is no judging or categorizing - and the urge to chronicle a history of complaints, or record signs or symptoms, does not occur. The second step includes assisting the patient with creating a metaphor for the condition or illness. A concrete image of the illness helps the patient and the healer understand the nature of the condition. In the third step, the healer constructs a ceremony that becomes the therapeutic intervention to "fight the illness." As a rule of thumb, the ceremony (intervention) that will be implemented depends on the images that the patient has used to describe the condition or his or her chief complaints.

The patient must be central to the ceremony; he or she is not a passive recipient of the intervention. Mehl-Madrona (1997) suggests that a bridge between Western and AIAN medicines should be embraced, and the wisdom of one should be used to inform the wisdom of the other. The foundation of this bridge must include the AIAN concepts that embrace the intimate connection and relational worldview, and its focus on the body, mind, and spirit. Kleinman (1996) had stressed that illness categories reflect cultural principles and practices. However, clinicians and researchers must be careful not to allow their own cultural biases to 
damage and convolute needed scientific research and therapies. Kleinman (1996) reports that many Plains American Indians hear the voice of a recently deceased relative, who calls them from the afterworld. This is a normative experience and is not pathological. However, if a Caucasian person were to report the same or a similar experience, it could be considered pathological, and a reason to consider further evaluation related to a severe mental illness. The key element here is contextual cultural beliefs and practices (APA, 2000; Brave Heart \& DeBruyn, 1998; Lester, 1995; Red Horse, 1992; Rieckmann, 2001; Whitbeck et al., 2002; Yates, 1987).

However, services such as these are not available in most health facilities - in fact, Western oriented practitioners, for the most part, are not cognizant of the pervasive practice of AIAN traditional medicine. The Western assessment data do not include these common practices despite the fact that AIANs rate their traditional healer's advice $61.4 \%$ higher than their Western physician's guidance. Significantly, only $14.8 \%$ of patients who receive services from healers tell their Western physician about their help-seeking from traditional healers (Gary, Baker, \& Grandbois, 2005; U.S. Department of Health and Human Services, 2001). Based on these trends, there is an obvious need to integrate traditional and Western contemporary health services into the existing health options for all AIAN people.

To help demonstrate the need for culturally competent care among AIAN people, I have compared AIAN and Western approaches to the assessment and treatment of a psychiatric disorder in mental health systems (see Table 3). (For a more detailed discussion, see Atkinson, Morten, \& Sue, 1998; Gary, Baker, \& Grandbois, 2005; Manson, 2000; Mehl-Madrona, 1997; Thompson, 1996; Thompson, Walker, \& Silk-Walker, 1993).

Much debate continues about mental disorders and behavioral problems among AIAN children, adults, and elders being directly linked to multigenerational historical trauma and cultural mayhem over the past several centuries. This concern should be more definitively developed into theories that could help guide culturally relevant prevention and treatment for mental health disorders, including the worldview of disturbances in balance and harmony. Theoretical propositions and frameworks that are developed by AIAN people should be encouraged and supported at governmental and scientific levels. Western scientific thought, heavily oriented in biological frameworks, could be espoused for the understanding of mental disorders that incorporate the lived experiences of AIANs. AIAN Nations have embraced the relational essence among the body, the spirit, the mind, and their culture for thousands of years. These 
TABLE 3. Comparison of Mental Health Treatment Approaches among AIAN and Western Systems

AIAN

Western

1. Ideally, treatment teams are traditional healers and indigenous people, aware of folkways and available when needed. The healers and mental health providers participate in the lived experiences of AIAN people. There are shared points of reference. The healer listens to the individual's story (history and clinical symptoms) and tries to understand all segments of the patient's frustrations and conflicts. The healer will construct a metaphor when the story is understood and verified by the individual (patient).

2. The local police have an atypical role in Treatment is provided away from mental health care: They are frequently the point of contact and they might, unfortunately, be the "first line" interventionists. Generally, they assist with transportation, and help with crisis stabilization. While this is not the ideal scenario, it is often the reality.

3. If requested, immediate and extended family members may be involved in the assessment and treatment process. The traditional healer designs an intervention that is specific to the patient's condition. If appropriate, the language of the AIAN person is used, with all of the metaphor, highly personal language, and contextual nuances included. The healer, with the help of the patient, will construct a ritual that will help the patient to "fight the illness."
Mental health providers are usually non-AIAN, live outside the community, and are available only $8 \mathrm{hrs} /$ day. The providers may not understand the context within which the individual lives, and his/her culture may not be well understood by the non-indigenous providers. Diagnoses and subsequent treatment might be compromised.

communities, with rigid schedules, and limited family involvement. Mainstream police are not trusted. Stigma related to mental illness could serve as a barrier to help seeking and treatment compliance; the double stigma of mental illness and minority status can sometimes influence inappropriate placement in the criminal justice system. Issues related to mental illness and manifest behaviors can be blurred and not fully understood within the context of the person's culture and acceptable practices. Inappropriate placement sometimes misdiagnoses and causes the criminalization of those with mental illnesses.

Counseling sessions are individualized and scheduled in advance. Data collection is mainly between the patient and the clinician and involves a psychiatric evaluation that results in a diagnosis. The data that are generated are compared with the western standard of diagnosing and treating psychiatric disorders, and the DSM-IV TR is used as the guidepost for this process. Discussing the patient's data with family members violates codes of confidentiality.

(Continued on next page) 
TABLE 3. Comparison of Mental Health Treatment Approaches among AIAN and Western Systems (Continued)

\begin{tabular}{l} 
AIAN \\
\hline As a rule of thumb, the ceremony \\
(intervention) that will be implemented \\
depends on the images that the patient \\
has used to describe the condition or \\
chief complaints. The patient is an \\
active participant in the intervention \\
(Mehl-Madrona, 1997). \\
4. Ideally, AIAN family members should \\
be actively involved in treatment. \\
Family could imply extended members \\
and even neighbors and friends. \\
Traditional healers, respected clergy, \\
and other indigenous people might be \\
invited to join the healing process. Time \\
is not a factor. Insurance eligibility, \\
bureaucratic rules, etc., do not exist. \\
Instead, the focus is on helping the \\
individual restore balance and harmony \\
to his/her life. The process continues \\
until the desired outcome is \\
attained.
\end{tabular}

5. Specific aims of the treatment plan are to bring harmony and balance to the individual and his/her family. The patient becomes the focus of attention and is supported by family, friends, and tribal community. These people are invested in the person's return to health and well-being.
Western

However, certain aspects of the interview/admission/treatment will necessitate family involvement, but the dominant theme across all treatment related activities is confidentiality. This concept may not easily lend itself to AIAN culture and preferred methods of treatment.

Confidentiality is a major consideration during treatment, thereby excluding family members. Insurance eligibility and bureaucratic rules are followed. Traditional healers and elders would have limited roles in the overall management of mental disorders. In some instances, indigenous workers might be involved but this is not standard.

Non-AIAN providers typically provide counseling. Many are not culturally competent, neither are they conversant in the preferred ways of diagnosing and treating mental disorders among AIAN populations. The overlap between physician and non-physician is variable and communications between the various providers differ in frequency and relevance. Continuity of care is compromised because of distrust that exists among AIANs and the mental health western establishment. There is, typically, a failure to connect with the AIAN lived experiences. Hence, a disconnect could exist between the patient and the provider.

(Continue on next page) 
TABLE 3. Comparison of Mental Health Treatment Approaches among AIAN and Western Systems (Continued)

\begin{tabular}{l} 
AIAN \\
\hline 6. Traditional healers and supporters can \\
remain for an indefinite period at a \\
place that is determined by all the \\
stakeholders. It could be in the person's \\
home and they could remain with the \\
person for hours, or days and beyond, in \\
the service of restoring the harmony and \\
balance to the individual [patient]. \\
Focus is on the patient and family \\
members. Since time is not a factor, \\
there is no tension related to hourly \\
charges, etc. \\
7. Clinics-some with undesirable \\
physical presentation, lack of AIAN \\
clinicians, and potential for \\
stigma-make AIAN persons' \\
participation in treatment difficult and \\
delayed. AIANs are aware that stigma \\
is an issue among Caucasians, and other \\
ethnic minority groups as well.
\end{tabular}

8. Debate continues about physical, mental, and behavioral problems among AIANs being linked to historical trauma and cultural mayhem. The education of a diverse workforce of AIAN mental health professionals, including nurses, should become a high priority at the federal and state levels of government. Theories and schools of thought that embrace and integrate AIAN culture into western medicine must be carefully developed and inculcated into all aspects of the healthcare system.
Western

Family members are typically not included in the overall treatment process and in all stages of treatment. Austere institutional settings within a public venue are the norm and many AIANs would prefer not to receive treatment in these environments. Due to other problems, such as difficulties with transportation, language, and payment, many AIAN people delay treatment, resulting in prolonged states of disharmony and imbalance.

Clinics will probably not address the issue of stigma or mental illness as expressed in AIANs. Clinicians do not adequately discuss how traditional and Western mental health approaches can be integrated into the treatment process. Social determinants of health such as poverty, socioeconomic status, the lack of education, poor overall health status, and so forth, will not be included in the treatment plan and goal setting.

Long-term approaches and follow up to the manifest problem are not addressed.

Theories that could guide culturally relevant prevention and treatment should be developed, including worldviews of balance and harmony. Theoretical frameworks and treatment approaches developed by AIAN scientists, researchers and clinicians should be supported by all levels of government and the scientific community.

Sources: Brave Heart and DeBruyn, 1998; Dixon and Roubideaux, 2001; Gary, Baker, and Grandbois, 2005; Joe, 2001; Lowe and Struthers, 2001; Smedley et al., 2003; Red Horse, 1992; The Sullivan Commission on Diversity in the Healthcare Workforce, 2004; U.S. Department of Health and Human Services, 2001; Yates, 1987. 
age-old cultural beliefs could be explored in a parallel manner, along with the underpinnings espoused by the National Institute of Mental Health: mind, body, and behavior (Cohen, 1961; Fabrega, 1974; Mezzich, Kleinman, Fabrega, \& Parron, 1996). Research funding is sorely needed to address gaps in the scientific literature as related to domains such as the availability and utilization of mental health services; the use of complementary and traditional medical approaches among the various AIAN Nations; and evidence-based studies that are built on culturally competent models (Gary, Baker, \& Grandbois, 2005; Kleinman, 1996; Lowe \& Struthers, 2001; Mezzich et al., 1996; Snowden \& Cheung, 1990; U.S. Department of Health \& Human Services, 2001). Responsible health professionals and governmental agents and agencies must quickly move to provide a higher level of health and mental health care to AIAN people (Borowsky, Resnick, Ireland, \& Blum, 1999; CDC, 2003a, 2003b; Coleman, Charles, \& Collins, 2001; Dinges, Atlis, \& Ragan, 2000; Duclos, LeBeau, \& Elias, 1994; Edmonson, 2000; NIMH, 2001).

\section{DOMAINS THAT IMPACT CARE}

This discussion concludes with a brief presentation of four domains that must be addressed if efforts to provide culturally competent and equitable care to AIAN people are to be realized. The domains include the federal trust responsibility; income, education, and poverty; access to health care; and health disparities.

\section{Federal Trust Responsibility}

The United States has a legal and moral obligation to provide health care services to AIAN people. There is already a federal trust responsibility in place that is the result of more than 800 ratified treaties, Presidential Executive Orders, and laws in accordance with the precepts of treaty-making authorities and international law (National Congress of American Indians, 2004). AIAN nations ceded vast amounts of land and resources to the United States Government in exchange for a commitment to provide health services and other legally binding obligations. The government's inattention to the signed treaties has helped to create significant health disparities, which produce higher mortality and morbidity rates among AIAN people, across many illness conditions (Kleinman, 1996; U.S. Department of Health and Human Services, 2001).

The realities of inadequate funding for health care continue to serve as one of the major barriers to adequate recognition and treatment of 
psychiatric disorders. Much of this reality is related to the terms of treaties simply not being adequately met. Hence, the promises that were made to the AIAN people by the United States government are flawed and should be re-established with AIAN people. Here is an example: The Indian Health Service (IHS) has a FY 2005 budget request of \$2.97 billion which falls well short of the level of funding that would permit AIAN health programs to achieve system parity with the majority of other American health systems (Democratic Policy Committee $\&$ Democratic Steering and Coordination Committee, n.d.; National Indian Health Board [NIHB], 2005; U.S. Department of Human and Health Services, 2005). If health needs were the variable used to calculate the budget, the baseline funds necessary to address basic health care needs for AIAN people would be around $\$ 19.4$ billion (U.S. Commission on Civil Rights, 2003).

Members of the National Indian Health Board (NIHB) stated that the greatest travesty associated with the deplorable health of AIAN people is that the majority of the causes of their high morbidity and mortality rates are preventable and treatable. However, services sufficient to provide even the most basic level of care are not available (Dixon \& Roubideaux, 2001; NIHB, 2005; Smedley et al., 2003).

\section{Income, Education, and Poverty}

AIAN populations are younger than their Caucasian counterparts because of higher overall mortality, less education, and lower incomes (Indian Health Service [IHS], 2000; Zuckerman, Haley, Roubideaux, \& Lillie-Blanton, 2004). Data from the 1997 and 1999 National Surveys of America's Families (NSAF) reveal that $38 \%$ of AIANs are children, compared with $28 \%$ of the Caucasian population. They also reported that $20 \%$ of AIANs live in families in which no adult graduated from high school (Urban Institute, 1999). In comparison, only 6\% of Caucasians live in similar circumstances. Furthermore, only about $25 \%$ of Caucasians live in families with incomes below $200 \%$ of the federal poverty level, but about $55 \%$ of AIANs have incomes lower than the national poverty level (Zuckerman et al., 2004). According to federally defined economic indicators of poverty, AIANs can be classified as "poorest of the poor" in this country (Atkinson et al., 1998; IHS, 2000; LaFromboise, 1998). AIAN people are influenced by the social determinants of health as described by Marmot and Wilkinson (1999). These variables include environmental factors, socioeconomic status, education, family relations, access to treatment, and others (Marmot \& Wilkinson, 1999; U.S. Department of Health and Human Services, 2000, 2001). 


\section{Access to Health Care}

Although the Indian Health Service (IHS) strives to provide comprehensive, high-quality health care services to AIAN people, it remains severely underfunded (IHS, 2000). Concerns over the quality of health care delivered to AIAN populations, and how access to services is attained, require immediate attention from the U.S. Congress, and all health professionals in this nation (IHS, 2000).

Approximately $60 \%$ of Native Americans rely on the IHS to provide for their health care needs, yet funding for IHS has not kept pace with medication cost inflation and population growth (U.S. Commission on Civil Rights, 2003). As a result, IHS services are under funded, and patients are routinely denied care (Democratic Policy Committee \& Democratic Steering and Coordination Committee, n.d.). The budget for clinical services is so inadequate that Indian patients are frequently subjected to a "life or limb" test. That is to say, their care is denied unless their life is threatened or they risk immediate loss of a limb. Care is denied or delayed until their condition worsens and treatment is costlier or, all too often, comes too late to be effective (Democratic Policy Committee \& Democratic Steering and Coordination Committee, n.d.).

A comparison between IHS appropriations per capita and other federal health expenditures in 2003 demonstrates that the per capita funding for Indian health is only $\$ 1,914$, about half the allotment of federal per capita funding for health care for federal prisoners. Figure 1 illustrates the disparity between per capita IHS spending and federal health expenditures for other healthcare systems in the United States.

Based on the data in Figure 1, it is clear that AIANs receive the least amount of federal assistance though their health burden is the most severe (NIHB, 2005). This becomes even more significant when considering that IHS reports that its service population is approximately 1.6 million AIANs (IHS, 2004), which is far less than the total number of AIANs reported by the U.S. Census (4.1 million). This difference is partly due to the location of most IHS facilities in rural areas, even though the majority of AIANs actually live in urban areas (Roubideaux, 2004). Forquera (2001) indicates that the IHS does try to address the needs of urban AIANs; it currently funds 34 urban Indian health programs in cities with large AIAN populations. The difficulty, however, is that only $1 \%$ of the IHS budget is earmarked for urban Indian programs.

As a rule, attaining relevant mental health care remains beyond the reach of most AIANs (Dixon \& Roubideaux, 2001; Gary et al., 2005; Grandbois \& Yurkovich, 2003; Manson, 2000; Smedley et al., 2003). 


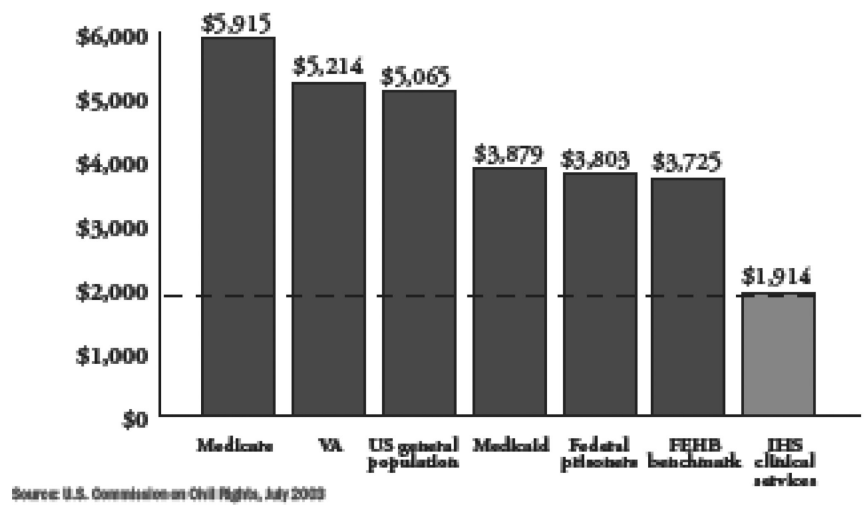

FIGURE 1. Comparison between IHS appropriations per capita and other federal health expenditures in 2003. From U.S. Commission on Civil Rights, 2003, as cited in Democratic Policy Committee \& Democratic Steering and Coordination Committee, Office of Senate Democratic Leader Tom Daschle, n.d., Health care: A special report. Retrieved June 1, 2005, from http://democrats.senate.gov/steering/images/na-forum/health-care.pdf. Reprinted with permission of the author.

In spite of the mortality and morbidity rates that exist among AIANs, they do not have adequate access to culturally competent mental health care for a variety of reasons (Grandbois \& Yurkovich, 2003; LaFromboise, 1998; Manson, 2000; Olson, Wahab, \& Gooden, 2003; Smedley et al., 2003). While greater than one-third of the demands on health services in AIAN communities involve mental health- and social services-related concerns, the IHS line item mental health budget has hardly increased in the last 20 years (Nelson, McCoy, Stetter, \& Vanderwagen, 1992).

Nelson et al. (1992) found that the high demand for services in many mental health programs, combined with the complexity and seriousness of mental health needs, frequently result in high rates of burnout and turnover among mental health professionals. As a result, staffing of mental health professionals remains at less than $50 \%$ of what is needed to provide minimally adequate ambulatory mental health services to American Indians (Nelson et al., 1992).

\section{Health Disparities}

AIANs' quality of life significantly lags behind their Caucasian counterparts (Brave Heart \& DeBruyn, 1998; Dixon \& Roubideaux, 2001; Smedley et al., 2003; U.S. Commission on Civil Rights, 2003; U.S. 
Department of Health and Human Services, 2001). Researchers, clinicians, and the U.S. Commission on Civil Rights further declared that the current health status of American Indian and Alaska Native people is a public health crisis. Inherent in the crisis are a multitude of mental health conditions: (a) suicidal rates are some of the highest in the nation (Gary et al., 2005); (b) rates of depression continue to rise among children, adults, and the elderly; (c) obesity and diabetes are at epidemic proportions; and (d) severe mental disorders such as schizophrenia and other forms of psychoses are not addressed from a perspective of cultural competence. This crisis requires focused national attention from the media, civic, and governmental groups, including the United States Congress. The responsibility to honor America's promises to provide for the health, education, and welfare of the American Indian and Alaska Native people must be shared by all Americans (U.S. Commission on Civil Rights, 2003; Smedley et al., 2003; U.S. Department of Health and Human Services, 2001).

However, that is not enough. In order to reduce and eliminate health disparities, issues related to workforce diversity must be confronted in a systematic and forceful manner. Here are the numbers: There are approximately 101 mental health professionals available per 100,000 Native Americans, compared with 173 mental health personnel per 100,000 Whites (U.S. Commission on Civil Rights, 2003). It is clear that AIAN mental health professionals remain a rarity, although their numbers are slowly increasing (Atkinson et al., 1998; U.S. Department of Health and Human Services, 2001).

The Ethnic Minority Mental Health Report (U.S. Department of Health and Human Services, 2001) documents that AIAN people are underrepresented in mental health research and clinical trials. The gap between research and practice is far worse for racial and ethnic minorities, but is especially pronounced for AIANs. There are too few AIAN scientists that are prepared for mental health research careers. Without their emic understanding of the AIAN worldviews, cultures, and needs, evidenced-based treatment and effective care cannot become a reality (U.S. Department of Health and Human Services, 2001).

AIAN people are woefully underrepresented in all mental health professions, including nursing. Of the estimated 333,368 ethnic minority Registered Nurses (12\%) in the profession, only 13,040 are AIAN people, which is less than four percent (Spratley, Johnson, Sochalski, Fritz, \& Spencer, 2000). The numbers of AIAN professional nurses who have earned doctorates and expertise in mental health and substance abuse disorders is estimated to be less than ten. These dismal statistics suggest a need for a national agenda that is dedicated to educating and 
supporting AIAN professionals in mental health and substance abuse disorders.

\section{CONCLUSION}

In summary, AIAN people are the first Americans, yet they are burdened with sickness and disease that are not present in other societal groups. Cultural competence is one major concern that must be addressed when considering new and more effective methods of providing health and mental health care to these first Americans. In order to provide culturally competent care, all health providers should become knowledgeable about the worldviews of AIANs. Importantly, the nation must honor its treaty agreements with AIAN Nations, provide better education and greater access to health care, and reduce health disparities.

\section{REFERENCES}

American Psychiatric Association. (2000). Diagnostic and statistical manual of mental disorders (4th ed., text rev.). Washington, DC: American Psychiatric Association.

Andrew, M. M., \& Krouse, S. A. (1995). Research on excess deaths among American Indians and Alaska Natives: A critical review. Journal of Cultural Diversity, 2(1), $8-15$.

Atkinson, D. R., Morten, G., \& Sue, D. W. (Eds.). (1998). Counseling American minorities. A cross-cultural perspective (5th ed.). Dubuque, IA: McGraw Hill.

Bhatara, V. S., Gupta, A., \& Brokenleg, M. (1999). The Hiawatha Asylum for insane Indians: The first federal mental hospital for an ethnic group. The American Journal of Psychiatry, 156, 767.

Borowsky, I. W., Resnick, M. D., Ireland, M., \& Blum, R. W. (1999). Suicide attempts among American Indian and Alaska Native youth: Risk and protective factors. Archives of Pediatrics \& Adolescent Medicine, 153, 573-580.

Brave Heart, M. Y., \& DeBruyn, L. M. (1998). The American Indian Holocaust: Healing historical unresolved grief. American Indian Alaska Native Mental Health Research, 8(2), 56-78.

Buchwald, D., Beals, J., \& Manson, S. M. M. (2000). Use of traditional health practices among Native Americans in a primary care practice. Med Care 2000, 38, 11911199.

Burhansstipanov, L., \& Satter, D. E. (2000). Office of management and budget racial categories and implications for American Indians and Alaska Natives. American Journal of Public Health, 90, 1720-1723.

Centers for Disease Control and Prevention. (2003a). Health disparities experienced by American Indian and Alaska Natives. Mortality Morbidity Weekly Report, 52(30), 697. Retrieved June 1, 2005, from http://www.cdc.gov/mmwr/preview/ mmwrhtml/mm5230a1.htm 
Centers for Disease Control and Prevention. (2003b). Injury mortality among American Indian and Alaska Native children and youth-United States, 1989-1998. Mortality Morbidity Weekly Report, 52(30), 697-701. Retrieved June 1, 2005, from www.cdc. gov/mmwr/preview/mmwrhtml/mm5230a2.htm

Clifford-Stoltenberg, C., \& Earle, K. (2002). Exploring the mental health needs of American Indian children and families: Site visits to two tribal communities. Retrieved June 1, 2005, from http://www.nicwa.org/policy/research/APA/apa_report.pdf

Cohen, H. (1961). The evolution of the concept of disease. In B. Lush (Ed.), Concepts of medicine: A collection of essays on aspects of medicine (pp. 159-169). New York: Pergamon.

Coleman, H., Charles, G., \& Collins, J. (2001). Inhalant use by Canadian aboriginal youth. Journal of Child \& Adolescent Substance Abuse, 10(3), 1-20.

Cross, T., (1997). Understanding the relational worldview in Indian families. Retrieved June 1, 2005, from http://www.casanet.org/program-services/tribal/relationalworldview-Inidan-families.htm

Democratic Policy Committee \& Democratic Steering and Coordination Committee, Office of Senate Democratic Leader Tom Daschle. (n.d.). Health care: A special report. Retrieved June 1, 2005, from http://democrats.senate.gov/steering/images/ na-forum/health-care.pdf

Dinges, N. G., Atlis, M. M., \& Ragan, S. L. (2000). Assessment of depression among American Indians and Alaska Natives. In R. H. Dana (Ed.), Handbook of crosscultural and multicultural personality assessment (pp. 623-646). Mahwah, NJ: Lawrence Erlbaum.

Dixon, M., \& Roubideaux, Y. (Eds.). (2001). Promises to keep: Public health policy for American Indians and Alaska Natives in the 21 st century. Washington, DC: American Public Health Association.

Duclos, C. W., LeBeau, W., \& Elias, G. L. (1994). American Indian adolescent suicidal behavior in detention environments: Cause for continued basic and applied research. American Indian and Alaska Native Mental Health Research: The Journal of the National Center Monograph Series, 4, 189-214; discussion 214-221.

Edmonson, J. (2000). Hopelessness, self-efficacy, self-esteem and powerlessness in relation to American Indian suicide. Unpublished doctoral dissertation, University of North Texas, Denton.

Fabrega, H., Jr. (1974). Disease and social behavior: An interdisciplinary perspective. Cambridge, MA: MIT Press.

Forquera, R. (2001). Urban Indian health: Issue brief prepared for the Henry J. Kaiser Family Foundation. Retrieved June 1, 2005, from http://www.kff.org/minorityhealth/ loader.cfm?url=/commonspot/security/getfile.cfm\&PageID=13909

Garcia Coll, C., \& Garrido, M. (2000). Minorities in the United States: Sociocultural context for mental health and developmental psychopathology. In A. J. Sameroff, M. Lewis, \& S. M. Miller (Eds.), Handbook of developmental psychopathology (2nd ed., pp. 177-196). New York: Kluwer Academic/Plenum.

Gary, F. A., Baker, M., \& Grandbois, D. M. (2005, March 28). Perspectives on suicide prevention among American Indian and Alaska native children and adolescents: A call for help. Online Journal of Issues in Nursing, 10. Retrieved June 1, 2005, from http://nursingworld.org/ojin/hirsh/topic4/tpc4_3.htm 
Grandbois, D. M., \& Yurkovich, E. E., (2003). Policy issues restricting American Indian rural mental health services. Rural Mental Health Journal, Winter, 20-25.

Hooper, K. (1991). Some old questions for the new cross-cultural psychiatry. Medical Anthropology, 5, 229-330.

Indian Health Service. (2000). Trends in Indian health 1998-1999. Retrieved June 1, 2005, from http://www.ihs.gov/PublicInfo/Publications/trends98/trends98.asp

Joe, J. R. (2001). Out of harmony: Health problems and young Native American men. Journal of American College Health, 49, 237-242.

Johnson, D. L., \& Johnson, C. A. (1965). Totally discouraged: A depressive syndrome of the Dakota Sioux. Transcultural Psychiatric Research Review, 2, 141143.

Josephy, A. M. (1991). The Indian heritage of America. Boston: Houghton Mifflin.

Kleinman, A. (1996). How is culture important for DSM-IV? In J. E. Mezzich, A. Kleinman, H. Fabrega, \& D. L Parron (Eds.), Culture \& psychiatric diagnosis: A DSM-IV Perspective (pp. 17-18). Washington, DC: American Psychiatric Press.

Kunitz, S. J. (1983). Disease change and the role of medicine: The Navajo experience. Berkeley, CA: University of California Press.

LaFromboise, T. D. (1998). American Indian mental health policy.In D. R. Atkinson, G. Morten, and D. W. Sue (Eds.), Counseling American minorities: A cross-cultural perspective (5th ed., pp. 137-158). Dubuque, IA: McGraw Hill.

Lester, D. (1995). Social correlates of American Indian suicide and homicide rates. American Indian and Alaska Native Mental Health Research, 6(3), 46-55.

Levine, S., \& Lurie, N.O. (Eds.). (1970). The American Indian today. Baltimore, MD: Penguin.

Lewis, T. H. (1975). A syndrome of depression and mutism in the Oglala Sioux. American Journal of Psychiatry, 132, 753-755.

Lowe, J., \& Struthers, R. (2001). A conceptual framework of nursing in Native American culture. Journal of Nursing Scholarship, 33, 279-283.

Manson, S. M. (2000). Mental health services for American Indians and Alaska Natives: Need, use and barriers to effective care. Canadian Journal of Psychiatry, 45, 617626.

Manson, S. M., Shore, J. H., \& Bloom, J. D. (1985). The depressive experience in American Indian communities: A challenge for psychiatric theory and diagnosis. In A. Kleinman and B. Good (Eds.), Culture and depression: Studies in the anthropology and cross-cultural psychiatry of affect and disorder (pp. 331-368). Berkeley, CA: University of California Press.

Marmot, M., \& Wilkinson, R. G. (Eds.). (1999). Social determinants of health. New York: Oxford University Press.

Mehl-Madrona, L. (1997). Coyote medicine: Lessons from Native American healing: New York: Simon and Schuster.

Mezzich, J. E., Klienman, A., Fabrega, H., \& Parron, D. L. (1996). Culture and psychiatric diagnosis: A DSM-IV perspective. Washington, DC: American Psychiatric Press.

National Indian Health Board. (Spring, 2005). Update. Health Reporter, 11(1), 5. Retrieved June 1, 2005, from http://www.nihb.org/docs/newsletter_spring_05. pdf 
National Institute of Mental Health. (2001). Blueprint for change: Research on child and adolescent mental health. Retrieved June 1, 2005, from http://www.nimh.nih.gov/ publicat/nimhblueprint.pdf

Natives National Congress of American Indians. (2004). 2004 annual report. Retrieved June 1, 2005, from http://198.104.130.237/ncai/resource/documents/ Annual_reportrev_2004.pdf

Nelson, S. H., McCoy, G. F., Stettler, M., \& Vanderwagen, W. C. (1992). An overview of mental health services for American Indians and Alaska Natives in the 1990s. Hospital and Community Psychiatry, 43, 257-261.

Norton, I. M., \& Manson, S. M. (1996). Research in American Indian and Alaska Native communities: Navigating the cultural universe of values and process. Journal of Consulting and Clinical Psychology, 65, 856-860.

Novins, D. K., Bechtold, D. W., Sack, W. H., Thompson, J., Carter, D. R., \& Manson, S. M. (1997). The DSM-IV outline for cultural formulation: A critical demonstration with American Indian children. Journal of the American Academy of Child and Adolescent Psychiatry, 36, 1244-1251.

O’Nell, T. D. (1989). Psychiatric investigations among American Indians and Alaska Natives: A critical review. Culture, Medicine and Psychiatry, 13, 51-87.

Olson, L., Wahab, S., \& Gooden, M. (2003). Intentional injuries in American Indian communities: A report with recommendations. Report submitted to the National Injury Prevention Tribal Steering Committee Indian Health Services, U.S.

Pedraza, S., \& Rumbaut, R.G. (1996). Origins and destinies: Immigration, race, and ethnicity in America. Belmont, CA: Wadsworth.

Red Horse, J. G. (1992). Treatment and prevention of suicide among American Indians. In E. W. Haller and L. P. Aitken (Eds.), Mashkiki: Old medicine nourishing the new (pp. 69-80). Lanham, MD: University Press of America.

Rieckmann, T. (2001). Explanatory style, coping, and depression in Navajo adolescents. Unpublished doctoral dissertation. The University of Utah, Provo.

Roubideaux, Y. (2004). A review of the quality of health care for American Indians and Alaska Natives. New York: The Commonwealth Fund.

Smedley, B. D., Stith, A. Y., \& Nelson, A. R. (Eds.). (2003). Unequal treatment: Confronting racial and ethnic disparities in health care. Washington, DC: The National Academies Press.

Snowden, L. R., \& Cheung, F. K. (1990). Use of inpatient mental health services by members of ethnic minority groups. American Psychologist, 45, 347-355.

Spratley, E., Johnson, A., Sochalski, J., Fritz, M., \& Spencer, W. (2000). The registered nurse population: Findings from the national sample survey of registered nurses. Rockville, MD: U.S. Department of Health and Human Services, Health Resources and Service Administration Bureau of Health Professions, Division of Nursing.

The Sullivan Commission on Diversity in the Healthcare Workforce. (2004). Missing persons: Minorities in the health professions. Retrieved June 1, 2005, from http://www.aacn.nche.edu/Media/pdf/SullivanReport.pdf

Thompson, J. W., Walker, R. D., \& Silk-Walker, P. (1993). Psychiatric care of American Indians and Alaska Natives. In A. C. Gaw (Ed.), Culture, ethnicity and mental illness (pp. 189-243). Washington, DC: American Psychiatric Press. 
Thompson, V. L. (1996). Perceived experiences of racism as stressful life events. Community Mental Health Journal, 32, 223-233.

Trimble, J. E., Manson, S. M., Dinges, N. G., \& Medicine, B. (1984). American Indian concepts of mental health: Reflections and directions. In P. B. Pedersen, N. Sartorius, \& A. J. Marsella (Eds.), Mental health services: The cross-cultural context (pp. 199220). Beverly Hills, CA: Sage.

Urban Institute. (1999). National surveys of America's families, 1997. Washington, DC: Author. Retrieved June 1, 2005, from http://www.urban.org/content/ Research/NewFederalism/NSAF/PublicUseData/PubUse.htm

U.S. Census Bureau. (February, 2002). The American Indians and Alaska Native population: 2000. Retrieved June 1, 2005, from http://www.census.gov/prod/2002pubs/ c2kbr01-15.pdf

U.S. Commission on Civil Rights. (2003). A quiet crisis: Federal funding and unmet needs in Indian Country. Retrieved June 1, 2005, from http://www.usccr.gov/ pubs/na0703/na0731.pdf

U.S. Department of Health and Human Services. (2000). Healthy people 2010. Retrieved June 1, 2005, from http://www.healthypeople.gov

U.S. Department of Health and Human Services. (2001). Mental health: Cultural, race, and ethnicity-A supplement to mental health: A report of the Surgeon General. Rockville, MD: Author.

U.S. Department of Health and Human Services, Indian Health Service. (2004). FY 2004 budget requests, justification of estimates for appropriations committees. Retrieved June 1, 2005, from http://www.ihs.gov/AdminMngrResources/ Budget/FY_2004_Budget_Justification.asp

U.S. Department of Health and Human Services, Indian Health Service. (2005). FY 2005 budget requests, justification of estimates for appropriations committees. Retrieved June 1, 2005, from http://www.ihs.gov/AdminMngrResources/Budget/ FY_2005_Budget_Justification.asp

Walker, R. D., \& Ladue, R. A. (1986). An integrative approach to American Indian mental health. In C. B. Wilkinson, (Ed.), Ethnic psychiatry (pp. 146-194). New York: Plenum.

Wallace, A. F. C. (1959). The institutionalization of cathartic and control strategies in Iroquois religious psychotherapy. In K. Opler (Ed.), Culture and mental health: Cross-cultural studies (pp. 63-96). New York: Macmillan.

Warren, P. N. (1996). Being with two spirits. Sacred Hoop Magazine, Issue Number 12. Retrieved June 1, 2005, from http://sacredhoop.demon.co.uk/HOOP-35/ Two-Spirits.html

Whitbeck, L. B., McMorris, B. J., Hoyt, D. R., Stubben, J. D., \& LaFromboise, T. (2002). Perceived discrimination, traditional practices, and depressive symptoms among American Indians in the upper Midwest. Journal of Health and Social Behavior, 43, 400-418.

Yates, A. (1987). Current status and future directions of research on the American Indian child. American Journal of Psychiatry, 144, 1135-1142.

Yellow Bird, P. (2001). Wild Indians: Native perspective on the Hiawatha Asylum for Insane Indians. Retrieved June 1, 2005, from http://www.mindfreedom.org/ pdf/wildindians.pdf 
Young, A. (1995). The harmony of illusions: Inventing post-traumatic stress disorder. Princeton, NJ: Princeton University Press.

Zuckerman, S., Haley, J., Roubideaux, Y., \& Lillie-Blanton, M. (2004). Health service access, use, and insurance coverage among American Indians/Alaska Natives and Whites: What role does the Indian Health Service play? American Journal of Public Health, 94(1), 53-59. 